\title{
Wake losses optimization of offshore wind farms with moveable floating wind turbines
}

\author{
S.F. Rodrigues ${ }^{\text {a,* }}$, R. Teixeira Pinto ${ }^{\text {a }}$, M. Soleimanzadeh ${ }^{b}$, Peter A.N. Bosman ${ }^{\text {c }}$, P. Bauer ${ }^{\text {a }}$ \\ ${ }^{a}$ DC Systems \& Storage Group, Delft University of Technology, Mekelweg 4, 2628 CD Delft, The Netherlands \\ ${ }^{\mathrm{b}}$ ECN, Westerduinweg 3, 1755 LE Petten, The Netherlands

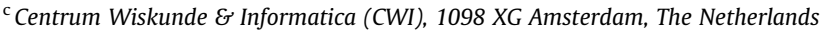

\section{A R T I C L E I N F O}

Article history:

Received 1 September 2014

Accepted 2 November 2014

Available online 17 November 2014

\section{Keywords:}

Moveable floating turbines

Nested optimization

Offshore wind energy

Turbine micro siting

Wake losses

\begin{abstract}
A B S T R A C T
In the future, floating wind turbines could be used to harvest energy in deep offshore areas where higher wind mean speeds are observed. Currently, several floating turbine concepts are being designed and tested in small scale projects; in particular, one concept allows the turbine to move after installation. This article presents a novel layout optimization framework for wind farms composed of moveable floating turbines. The proposed framework uses an evolutionary optimization strategy in a nested configuration which simultaneously optimizes the anchoring locations and the wind turbine position within the mooring lines for each individual wind direction. The results show that maximum energy production is obtained when moveable wind turbines are deployed in an optimized layout. In conclusion, the framework represents a new design optimization tool for future offshore wind farms composed of moveable floating turbines.
\end{abstract}

(c) 2014 Elsevier Ltd. All rights reserved.

\section{Introduction}

The need for steadier and higher mean wind speeds has been pushing the offshore wind industry towards areas located further from the coast [1]. In fact, both the average distance to shore and water depth of offshore wind projects has been increasing since the industry first steps (Fig. 1). However, current turbine grounded support structures are only economical viable to certain water depths ranges [2].

With the desire of moving to locations with deeper water depths, in an economically viable way, floating wind turbines concepts have appeared in the last years. Currently, there are several floating turbine concepts being developed and tested in pilot projects $[3,2]$. One of these floating turbine concepts is developed by the IDEOL company [4]. This specific design takes another advantage from the fact that a flowing turbine is not bottom-fixed to the seabed: it allows the turbine to have a certain mobility freedom even after its installation [4].

To reduce costs, e.g. cabling and area rental costs, turbines tend to be packed in wind farms. However, installing turbines close to each other causes interferences such as wake losses through shadowing. For example, the efficiency of the Danish Horns Rev I

\footnotetext{
* Corresponding author.

E-mail address: S.M.FragosoRodrigues@tudelft.nl (S.F. Rodrigues).
}

offshore wind farm is $89 \%$ of what the same turbines would produce if installed alone [5]. Thus, it is important to reduce the wake losses in far and large offshore wind farms. One possible strategy to reduce wake losses is to optimize the wind farm layout.

The wind farm layout optimization problem has been intensively studied in the last years [6-15]. More specifically, the first work that dealt with the wind farm layout problem was carried out back in 1994 [16]. The wind farm area was grid-discretized and the optimizer was set to obtain layouts that would increase the wind farm efficiency. The first work that considered the wind farm space as a continuous space was carried out in [17], whereas the first optimization approach tailored for offshore environments was presented in [18].

Although a great deal of research has been conducted in the wind farm layout optimization problem, all investigations solely considered the possibility of optimizing the turbine locations before construction. Hence, so far no strategy has been developed which considers the possibility of moving the wind turbines after the project commissioning. This work presents a novel optimization framework for offshore wind projects composed of moveable wind turbines.

The work is organized as follows: the next section introduces the different types of floating wind turbines that currently exist, followed by a detailed explanation of the moveable wind turbine concept. Thereafter, in Section 3, the novel optimization framework is proposed. Section 4 presents the wake loss models used 
in this work, whereas Section 5 presents a case study specifically designed to evaluate the proposed approach. In Section 6 the results are presented and an analysis is carried out. The article closes with general conclusions and recommendations for offshore wind and future research.

\section{Floating wind turbines}

Existing commercial-size offshore wind farms make use of grounded substructure concepts to support their turbines. Such substructures become very expensive and difficult to engineer as the water depth increases. Hitherto, water depths higher than $50 \mathrm{~m}$ require floating support structures. In fact, as shown in Fig. 2, only a demonstration offshore project, Beatrice Demonstration, uses grounded support structures at a location with an average water depth higher than $40 \mathrm{~m}$ [3].

Many countries have a limited number of suitable sites in sufficiently shallow water to allow economically viable fixed substructures. Within Europe, much of the Mediterranean and Atlantic basins as well as Norway face this difficulty [19]. In the long term, it is anticipated that floating structures will become prominent in the offshore wind market [19]. There are several advantages for using floating turbines:

- Access to previously inaccessible places where there is stronger yet less turbulent winds [20].

- More flexible construction and installation phases [19].

- Possible commissioning and assembly at the quayside, avoiding the need for heavy-lift jack-up or dynamic positioning vessels, further reducing the cost and risk of deployment activities [20].

- Avoiding piling activities during installation and an easier decommissioning processes lead to reduced environmental impacts and sea life disturbance.

- Geotechnical requirements are reduced since core sampling is only needed at the anchor positions, as opposed to the necessity of deep core sampling at every pile site [20].

Nonetheless, there are several challenges related to floating wind turbines. For example, the increased wind and wave-induced motion, the added complexity of the design process, electrical infrastructure design and costs (in particular the flexible cable), construction, installation and O\&M procedures [19]. However,
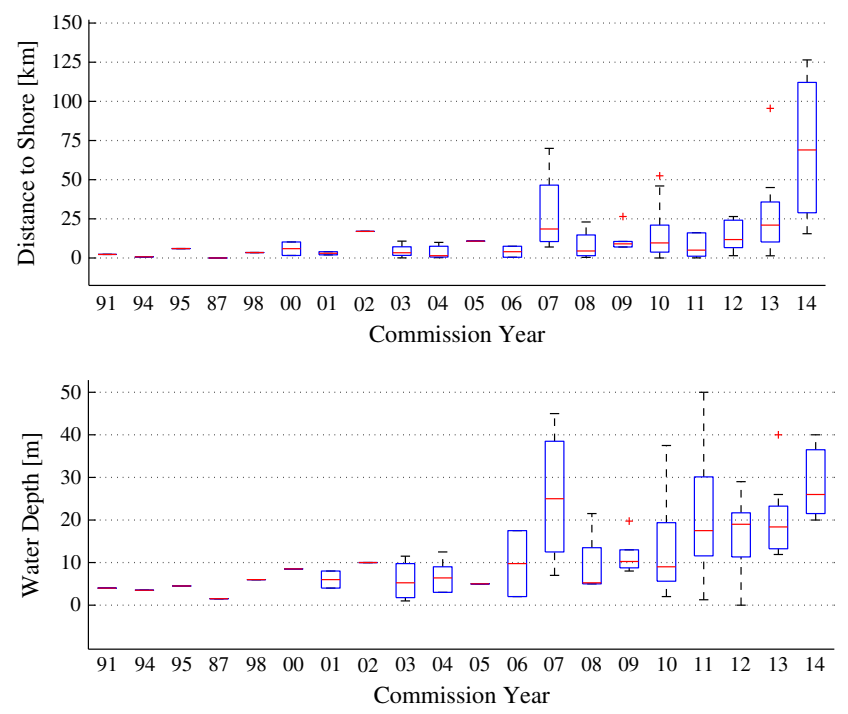

Fig. 1. Average distance to shore and water depth for commissioned offshore wind projects: aggregated values for all the projects commissioned in the same year $[23,58]$.

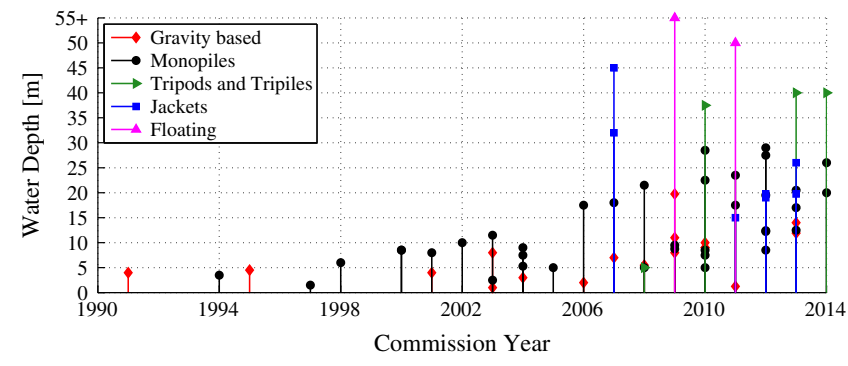

Fig. 2. Average water depth per offshore project $[23,58]$.

increased know-how and standardization practices will contribute to overcoming these challenges. Furthermore, it is also expected that a higher energy production will be achieved since the floating turbines will be deployed at sites with higher mean wind speeds. Currently the existing floating concepts may be categorized in three main types [21]:

- Buoyancy: employs a barge type device with catenary mooring lines.

- Mooring Line: under water chains or tethers connect the buoyant body to a counterweight that lies on the seabed [2]. With the buoyant body semi-submerged in the water, the necessary uplifting force is created, keeping the chains constantly tensioned [22].

- Ballast: uses spar buoy platforms with catenary mooring anchors.

\subsection{Moveable wind turbine concept}

IDEOL developed a new floating turbine concept, which allows the structure to move along its mooring lines [4]. Fig. 3a shows the basic version of a moveable turbine, which only allows for linear movements (one degree of freedom). This system is easier to operate since the turbine position is set by only one parameter, e.g. the distance from one the anchoring positions. Fig. 3b illustrates a more complex design which, by rearranging the anchoring positions, allows the turbine to cover a triangular area. This new anchoring configuration gives two degrees of freedom to the turbines, thus it allows them to move in two directions. Although, this system results in a higher maneuverability of the turbine, it increases the control complexity since two coordinates have to be set to position the turbine.

With this mobility, it becomes possible to optimize the wind farm layout based on different environmental data, e.g. wind and tidal direction. Hence, this solution allows for wake losses reduction, leading to an increased annual energy production. On the other hand, this concept is more complex than a similar floating concept due to the extra mobility machinery and attached complexity. Furthermore, they are logistically more complex, since it requires a system operator to move the turbines according to the wind direction. Nonetheless, reducing wake losses through a real time wind farm layout optimization according to the wind direction may bring energy gains which might overcome the shortcomings.

The wind direction is a key factor for the turbine mobility approach. Since the turbine mobility is somehow limited, the layout adjustment may be limited to more persistent wind direction alterations while disregarding fast wind direction transients. Therefore, the decision of moving the turbines should be based on data from meteorological masts and weather forecast to guarantee that there is an energy generation benefit to the repositioning. 


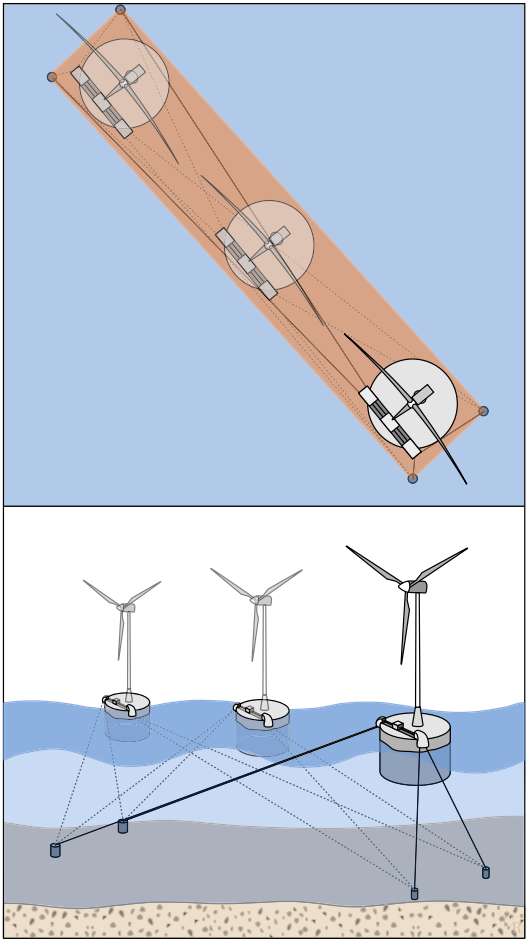

(a) 1 degree of freedom

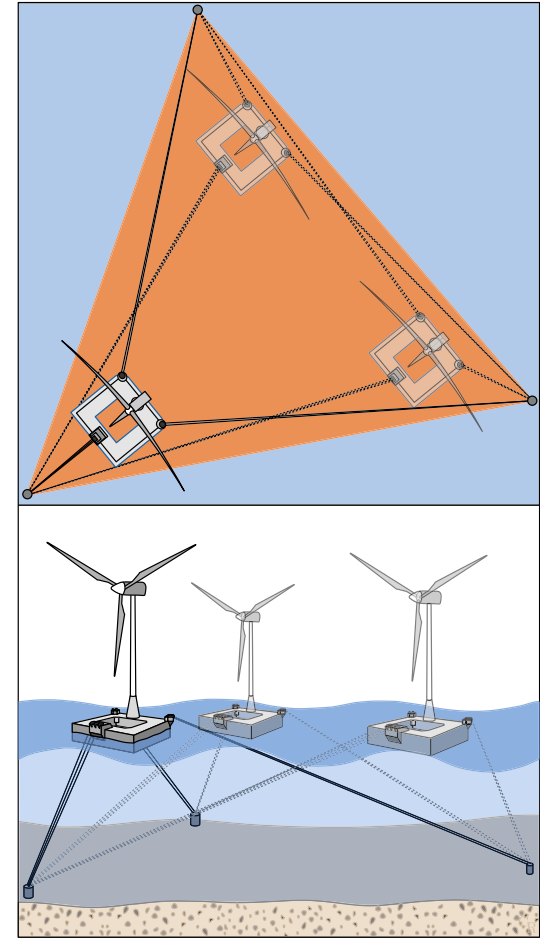

(b) 2 degrees of freedom

Fig. 3. Two IDEOL concepts for a moveable and floating wind turbine [4]. The figures show three different turbine positioning for both concepts.

\section{Wind farm layout optimization framework}

The proposed optimization framework here presented makes use of the advantaged brought by moveable wind turbines: it optimizes the turbines real-time location according to the wind direction. The framework has an integrative design strategy since it optimizes the positions of the turbine within their mooring lines and the turbines anchoring locations.

Current offshore wind farms are composed of dozens of turbines [23], which makes the optimization variables increase rapidly (e.g. the turbine locations). In fact, solving the wind farm layout optimization problem to optimality is very difficult since it falls under the combinatorial optimization problem class [24]. Therefore, the wind farm layout problem is not suitable to be solved through deterministic algorithms [24]. A solution, widely use in academia, is the use of stochastic algorithms, where randomness is included in the process [25].

An evolutionary strategy called Covariance Matrix Adaption (CMA-ES) was used in the proposed framework. The CMA-ES is one of the most powerful evolutionary algorithms for real-valued single-objective optimization of non-linear and non-convex functions $[26,8]$ and it has been applied in different fields of engineering $[8,27]$. Fig. 4 presents a flowchart of the CMA-ES algorithm.

\subsection{Nested optimization}

One might optimize first the locations of the turbines and after optimize the positions within the mooring lines for each wind direction; however, such approach represents a simplification which may create constraints in the solution space. The optimal solution for each individual problem is not necessarily the optimal solution for the complete problem.

A nested optimization framework is proposed in this work to simultaneously optimize the turbine positioning. An outer optimization loop is responsible for first establishing the turbines

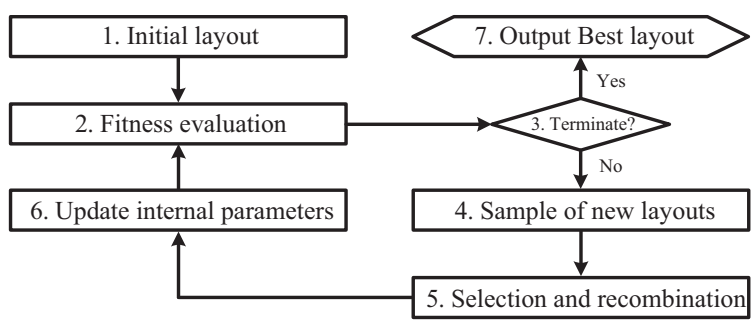

Fig. 4. Flowchart of the CMA-ES algorithm.

anchoring positions, whereas an inner loop optimizes the turbine location within its mooring lines for each wind direction. Fig. 5 shows the interactions between the two nested CMA-ES algorithms and both optimization loops are explained next.

\subsubsection{Outer optimization loop}

The CMA-ES of the outer optimization loop is set to optimize the anchoring locations. To do so, the optimization variables of this problem are the central point of the anchoring locations and the rotation angle. The encoded solutions have the following structure:

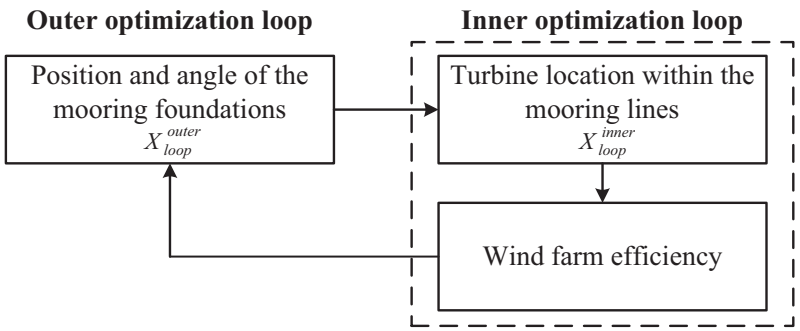

Fig. 5. Proposed nested optimization approach in which both the mooring line positions and the turbines locations are simultaneously optimized. 
$X_{\text {loop }}^{\text {outer }}=\left[\begin{array}{lllllllll}x_{1} & \cdots & x_{n} & y_{1} & \cdots & y_{n} & \theta_{1} & \cdots & \theta_{n}\end{array}\right]$

where $\left(x_{1}, y_{1}, \theta_{1}\right)$ and $\left(x_{n}, y_{n}, \theta_{n}\right)$ correspond to the central points and angles of the anchoring locations of the first and $n$-th turbines, respectively.

\subsubsection{Inner optimization loop}

The inner loop CMA-ES receives as input the position and angles of the anchoring locations. Thereafter, it optimizes the locations of the turbines within the mooring lines to reduce wakes losses. The inner loop solutions are encoded as:

$X_{\text {loop }}^{\text {inner }}=\left[\begin{array}{llllll}a_{1} & \cdots & a_{n} & b_{1} & \cdots & b_{n}\end{array}\right]$

where $\left(a_{1}, b_{1}\right)$ and $\left(a_{n}, b_{n}\right)$ correspond to the coordinates within the mooring lines of the first and $n$-th turbines, respectively.

Fig. 6 depicts the optimization variables for a $k$-th turbine with one and two degrees of freedom. In Fig. 6a, it can be seen that outer optimization loop defines the location of the turbines, giving the inner loop only the possibility of optimizing the turbine location along a straight line. On the other hand, with two degrees of freedom, the inner loop optimizes the location of the turbine within an area (see Fig. 6b).

\subsection{Optimization goal}

The maximization of the wind farm production is one of the most common optimization goals and it has been widely used in academia and in commercial software $[18,28,29]$. This work uses a similar optimization goal, the maximization of the wind farm efficiency, which is calculated as the ratio between the wind farm production with and without wake losses [7,30]. The wind farm production is computed as the mean power output for all wind directions and then scaled to account for a given wind direction frequency of occurrence. The ideal wind farm production is obtained as the power production of a single wind turbine (without wake losses) multiplied by the number of turbines in the wind farm. Finally, the wind farm efficiency is calculated by:

$\eta_{W F}=\frac{P_{\text {farm }}}{n \times P_{\text {turb }}^{\text {ideal }}}$

where $\eta_{\text {farm }}$ is the wind farm efficiency, $P_{\text {farm }}$ is the farm total power production and $n \times P_{\text {turb }}^{\text {ideal }}$ represents the power produced by $n$ turbines without shadowing effects.

\subsection{Constraints}

To obtain feasible wind farm layouts, the following constraints - displayed in Fig. 7 - were implemented:
- A minimum distance between neighboring turbines is required at all times - including both the default central locations and the optimized layouts - to guarantee the well-function and integrity of the turbines. In this work, the minimum separation is considered equal four times the turbines rotor diameter, however, this value is turbine dependent and should be provided by the manufacturer.

- The turbines have to be placed inside the farm area. For the mobile turbines case, the central point of the manoeuvrable area has to be located within the wind farm area. Nevertheless, the turbines are allowed to temporarily move to external positions.

\section{Wake losses modeling}

Installing turbines in closes vicinities causes interferences such as wake losses through shadowing. For example, the Danish Horns Rev I offshore wind farm produces circa $89 \%$ of the energy that the same turbines would produce if no wake losses occurred [5]. Hence, it is important to analyze and reduce the wake losses in far and large offshore wind farms.

Currently, there is a wide variety of models to calculate, with different accuracy levels, the wake losses inside wind farms [3137]. Examples of wake losses models to calculate the wind deficits due to wakes inside wind farms include the Jensen model (also known as Park model) [38], Eddy viscosity model [39], Frandsen et al. model [40], deep-array wake model [41] and the Larsen model [42]. These engineering models, due to their simplified wake speed deficit approach, offer fast calculation times and are able to provide a preliminary description of the far wake regime (4-6 rotor diameters) [35]. Other models were built to provide medium-fidelity results, namely the Dynamic Wake Meandering model [43] and several other approaches based on the actuator disk model [44,45].

Computational fluid dynamics (CFD) models stand in the highfidelity end [34]. The CFD models solve the parabolized NavierStokes equations which that may take various hours to compute in a large wind farm. Examples of CFD models are the Simulator for Offshore Wind Farm Applications (SOWFA), a modular and open-source tool developed by NREL [46], the EllipSys3D developed by DTU and Risø [31] and FarmFlow developed by the Energy Research Centre of the Netherlands (ECN) [47]. Finally, high-resolution models based on large eddy simulations (LES models) offer the highest fidelity but may take several weeks to complete [48].

CFD and LES approaches represent the most accurate tools to calculate turbine wakes and may be used for detailed studies such as: interactions between a turbulent flow and a rotor blade; the interaction between multiple wakes; or validation and calibration of simpler models $[5,48]$. However, a major disadvantage of such high-fidelity simulations is the excessive computational burden.
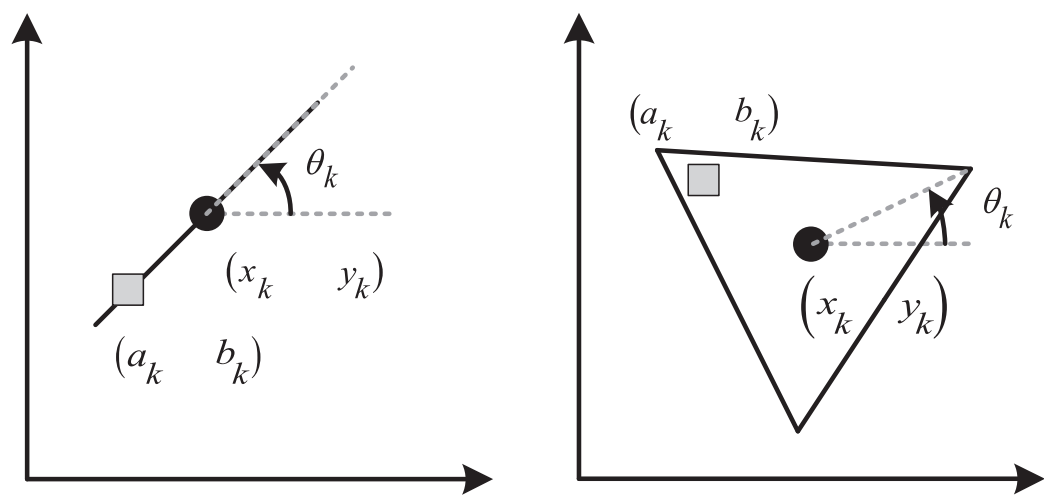

Fig. 6. Optimization variables used to obtained improved wind farm layouts for a $k$-th turbine. 


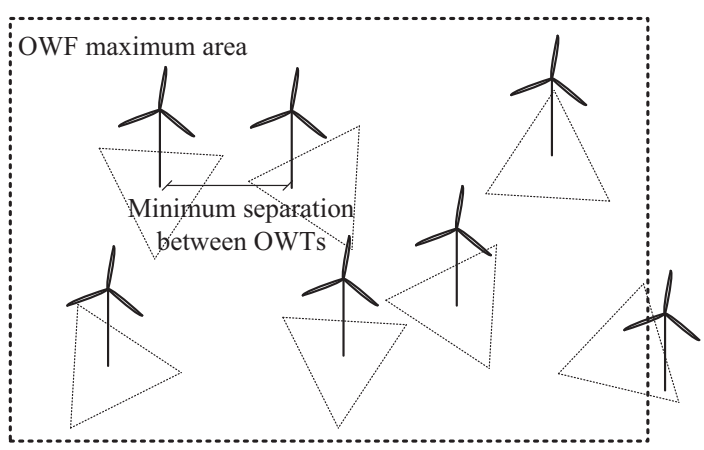

Fig. 7. Problem constraints taken into consideration to guarantee the feasibility of the optimized layouts.

Such drawback is further heightened when these models are employed to optimize the design of a large offshore wind farm, which requires a great deal of evaluations of the annual energy production [8].

Two models which sit in both extremes of the spectrum are used in this work to calculate the wake losses inside an offshore wind farm. The Jensen model is employed during the optimization routine, whereas FarmFlow is used to verify the efficiency of the optimized wind farm layouts. A brief description of both models is provided next.

\subsection{Jensen model}

The Jensen model, which was originally proposed in 1983 , is a simplified and fast manner of calculating the wind speed inside the wake of a wind turbine [38]. This model, due to this ease of implementation and fast computation has been widely adopted in wind farm modeling [49,30,50-54].

\subsection{FarmFlow}

FarmFlow, which is an improved version of the UPMWAKE model [55], solves the parabolized Navier-Stokes equations in all three dimensions, while the turbulent processes in the wake are modeled with a $k-\epsilon$ turbulence model. The performance of FarmFlow has been evaluated and compared to the commonly used models for predicting wind speed decrease inside turbines wakes $[37,33]$.

\section{Case study}

The case study, whose details are given next, was run in an i7laptop with $16 \mathrm{~GB}$ ram on Windows 7.

\subsection{Wind farm}

The proposed optimization framework was tested in a mediumsized offshore wind farm of $180 \mathrm{MW}$ installed power and a squareshaped area with $5 \mathrm{~km}$ side. The farm is composed of 36 identical turbines with a rated power of $5 \mathrm{MW}$. The turbines have a hub height of $90 \mathrm{~m}$ and a $126 \mathrm{~m}$ rotor diameter. Fig. 8 presents the turbine power curve and thrust coefficient for the operational wind speeds.

In the initial default wind farm layout the wind turbines were placed in a grid with $1 \mathrm{~km}$ distance between them and the angles for the mooring lines were set to the reference value (see Fig. 6). The wind farm was considered to be a continuous space, whereas the mooring lines are considered to be $50 \%$ longer than the turbine rotor diameter.

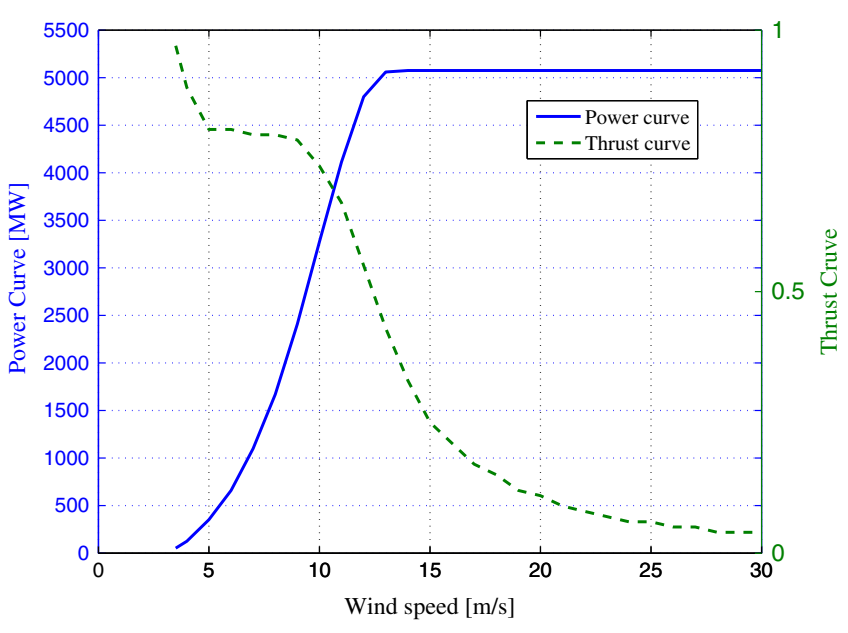

Fig. 8. Wind turbine power and thrust curves.

\subsection{Wind rose}

The proposed framework relies on the wind resource existing at the offshore site to obtain optimized layouts. The wind resource used - displayed in Fig. 9 - is based on measurement data collected during four years at the offshore platform Fino 1, located in the North Sea [56].

\subsection{CMA-ES}

The outer loop CMA-ES was run for $24 \mathrm{~h}$, whereas the inner loop algorithm was given 100 iterations per wind direction and solution. All remaining parameters of the CMA-ES algorithm were set to their default guideline values [57].

\subsection{Scenarios}

Six different scenarios were considered for the case study. Scenario 1 represents a standard grid-based wind farm project. The turbines locations are not optimized neither have the ability to move after installation. In Scenario 2, the turbine locations are optimized but no turbine mobility is considered. Contrarily, Scenarios 3 and 4 use the standard grid layout but make use of the

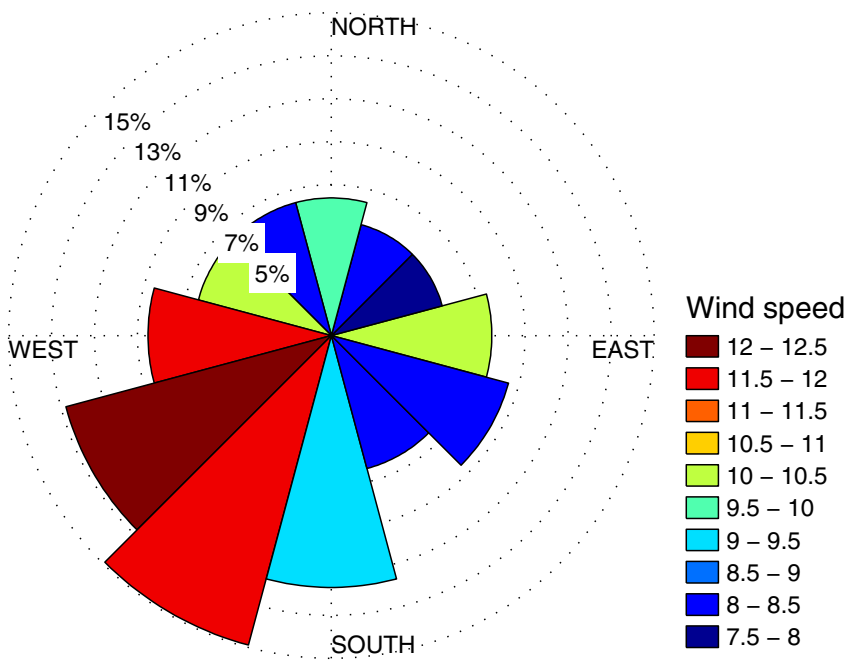

Fig. 9. Wind rose with average wind speeds and frequencies. North is the zero degree direction for the wind rose. 
moveable wind turbine. Finally, for Scenarios 5 and 6, an integrative optimization approach is used which encompasses both the turbines anchoring positions and the turbines location within the mooring lines. Table 1 summarizes the characteristics of each scenario.

\section{Results}

This section presents the results obtained for the six different scenarios. Fig. 10 shows the optimized layouts, whereas Fig. 11 depicts the overall wind farm efficiencies for the difference scenarios. The wind farms' efficiency, for each wind direction, is shown in Fig. 12.

\subsection{Jensen model}

According to the Jensen model, the regular wind farm layout has the lowest wind farm efficiency (Fig. 11). In Fig. 12(a) it is possible to observe that the standard grid layout has very low wind farm efficiencies for the directions where the wind is aligned with the turbine rows. The wind farm layout composed of fixed turbines and optimized layout has the second highest wind farm efficiency, only surpassed by Scenario 6. For Scenarios 3 and 4, where the turbines are positioned in the grid layout, the optimization was able to decrease the wake losses for the directions where the wind is aligned with the turbine rows, while it also increased the energy capture for the other angles (Fig. 12(a)).

\subsection{FarmFlow}

According to FarmFlow, Scenario 1 has the highest efficiency between $240^{\circ}$ and $330^{\circ}$ (Fig. 12(b)). This may be explained by the fact that the highest mean wind speeds are felt in these directions and therefore, the impact of turbines for the wake generation is the weakest (due to the lower thrust coefficients, Fig. 8). Furthermore, the grid layout benefits from the fact that the turbines have greater spacings for these angles. Hence, a lower wind farm efficiency is expected in case the main wind section is aligned with the turbine rows.

Scenarios 3 and 4 presented the lowest efficiencies of the case studies according to FarmFlow, whereas Scenarios 2, 5 and 6 had not only the highest energy productions (Fig. 11) as well as the lowest efficiency variabilities according to both models (Fig. 12).

Fig. 11 shows that there is an absolute difference of the wind farm efficiencies according to the two wake models. Furthermore, there were also some relative differences between them. The highest discrepancies between the models have occurred in case studies 3 and 4. According to the Jensen model, all optimized layouts performed better than the standard layout, whereas FarmFlow gave a lower efficiency for these two cases.

In these scenarios, the wind turbines are placed in a grid layout, hence, the distances between the turbines vary much less than in Scenarios 2, 5 and 6. Fig. 12(b) shows that Scenarios 1, 3 and 4 have lower efficiencies for the wind directions with lower mean speeds $\left(0-150^{\circ}\right)$ and yet they yield comparable efficiencies with the other

Table 1

Case study scenarios.

\begin{tabular}{llll}
\hline Scenario & Optimized locations & Moveable turbines & Degrees of freedom \\
\hline 1 & No & No & 0 \\
2 & Yes & No & 0 \\
3 & No & Yes & 1 \\
4 & No & Yes & 2 \\
5 & Yes & Yes & 1 \\
6 & Yes & Yes & 2 \\
\hline
\end{tabular}

scenarios in the main wind directions $\left(180-330^{\circ}\right)$. By comparing the results of both models in Fig. 12, it is possible to observe that the Jensen model did not accurately depicted the wake losses for Scenarios 3 and 4 for the wind directions in the $0-150^{\circ}$ range. Differently, in the scenarios in which the wind farm layout is also optimized, both models are in a higher concordance. Therefore, one might conclude that the Jensen model offers a poorer accuracy for this specific range of distances in combination with lower mean wind speeds (higher turbine shadowing effect).

The accuracy of different wake models has been the object of several previous studies. For example, Andersen et al. [31] conducted a comparison of different engineering wake models (including the Jensen model) and CFD simulations. They demonstrated that the highest discrepancies between the Jensen and the CFD models were observed around distances of 4-8 rotor diameters and for higher thrust coefficients, which is in line with the results obtained in this paper. Nonetheless, these studies have been conducted with very narrow setups, such as fixed turbine thrust coefficients and constant distances between turbines. Therefore, it is very difficult to conclude which are the parameters that contribute the most for the differences between the models in the present case study.

Albeit the differences between the two wake loss models, one might say that turbine mobility will, in the worst case scenario, generate the same energy as a wind farm composed of fixed turbines. The results obtained with the FarmFlow model appear to indicate that floating mobility generate benefits if the turbine layout is coordinately optimized, whereas with the Jensen model all the optimized layouts perform better than the standard layout. Furthermore, according to both models the highest energy improvements were observed when the wind farm layout was optimized using moveable wind turbines.

The relative differences in the results were originated from the fact that the Jensen model was used in the optimization process and the FarmFlow was only employed to validate the efficiency of the final layouts. These results demonstrate the importance of developing fast-accurate models which may be applied for the optimization of future large offshore wind farms. The impact of the energy efficiency on the project levelized production cost (LPC) is discussed next.

\subsection{Impact on the levelized production cost}

The LPC is the project lifetime cost per unit of power generated and may be calculated as $[17,18]$ :

$L P C=\frac{1}{A E P}\left(\frac{C A P E X}{a}+O P E X\right)$

where AEP is the annual energy production, CAPEX is the capital expenditure, OPEX is the operational and maintenance costs, $a$ is the annuity factor $a=\left(1-(1+r)^{-n}\right) r^{-1}, r$ is the interest rate and $n$ is the wind farm exploitation time.

Assuming the annuity factor as a weighting factor $\omega_{1}$ and the $\mathrm{O} \& \mathrm{M}$ costs to be a percentage of the investment costs, $\omega_{2}$, yields:

$L P C=\frac{1}{A E P}\left(\omega_{1} \cdot C A P E X+\omega_{2} \cdot C A P E X\right)$

Summing the two weighing factors the LPC becomes:

$L P C=\frac{C A P E X}{A E P} \cdot \omega$

Assuming an interest rate of $7 \%$, a wind project exploration time of 20 years and the O\&M costs to be $2 \%$ of the CAPEX [18,17], a weighting factor of $\omega=0.114$ is obtained. Table 2 shows the variation of the LPC when considering an initial LPC value of $90 € / \mathrm{MWh}$ for the initial standard layout, constant CAPEX for the different sce- 


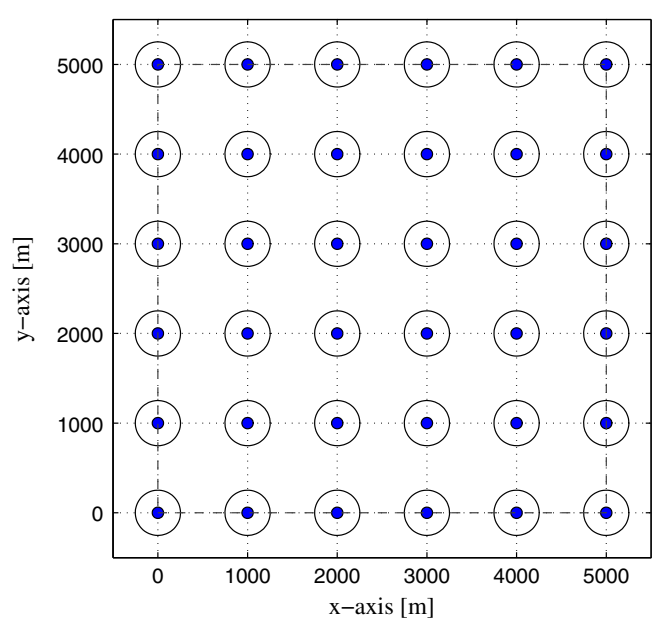

(a) Scenario 1

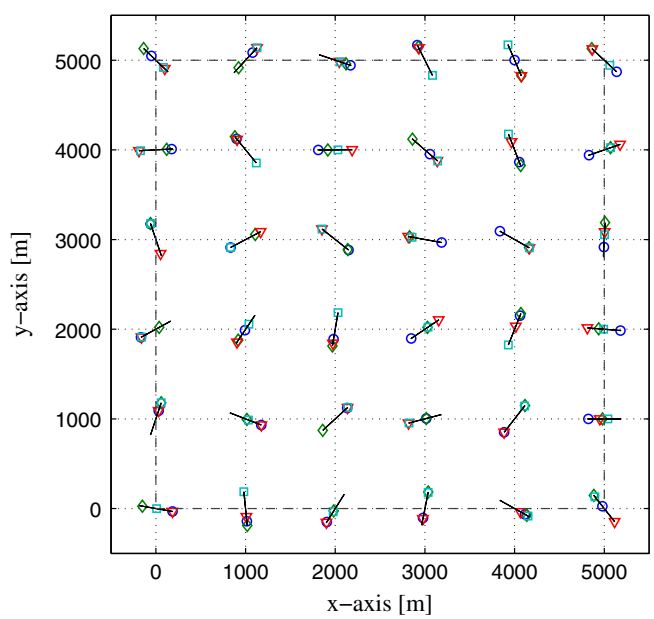

(c) Scenario 3

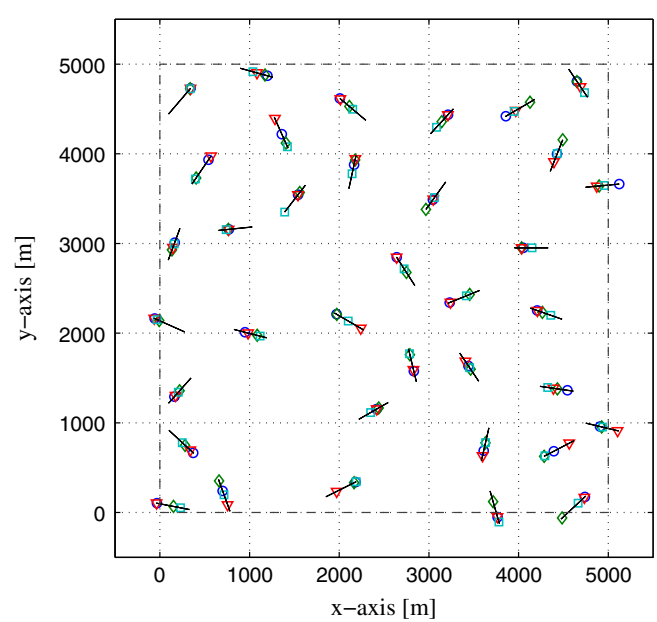

(e) Scenario 5

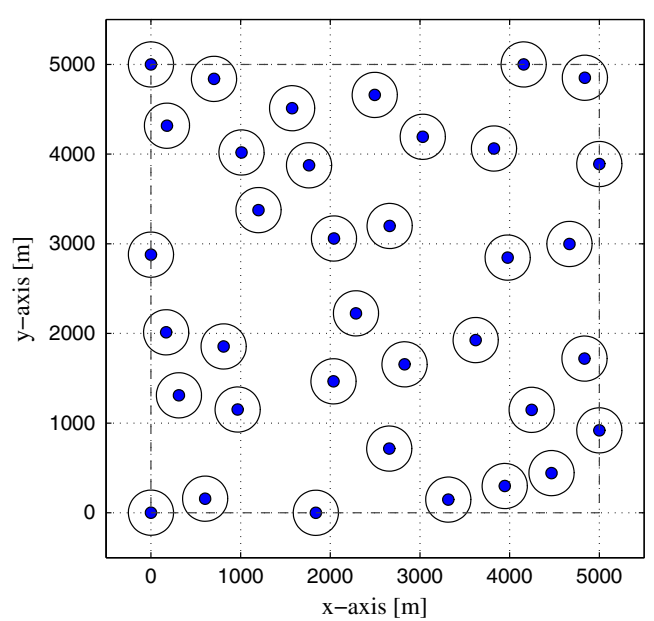

(b) Scenario 2

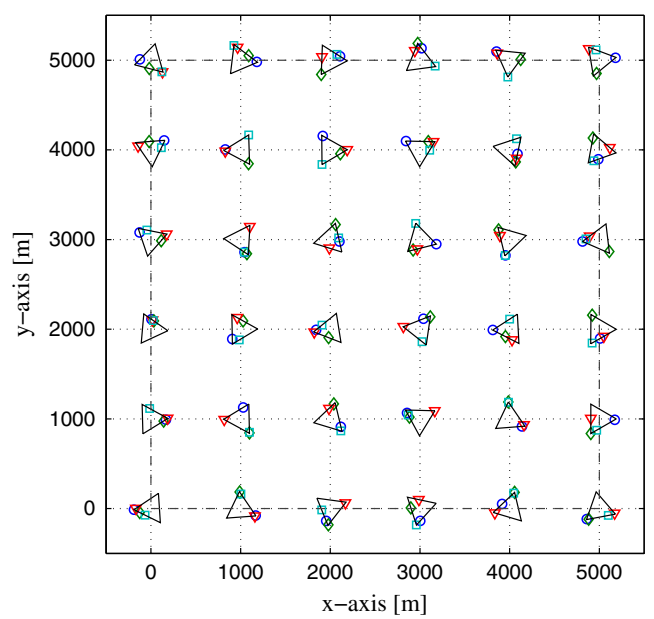

(d) Scenario 4

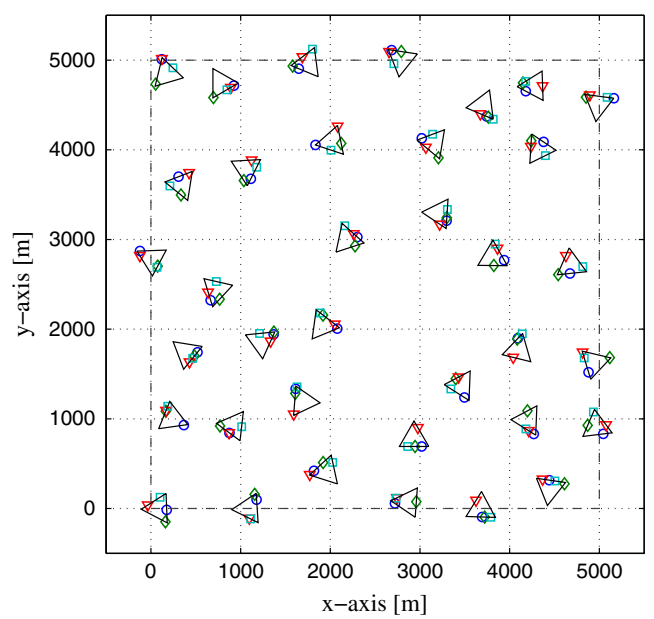

(f) Scenario 6

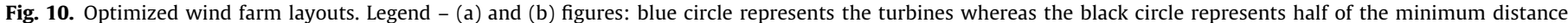

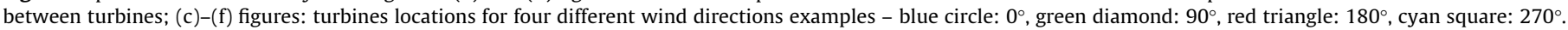
(For interpretation of the references to colour in this figure legend, the reader is referred to the web version of this article.)

narios and a weighing factor of $\omega=0.114$. The wind farm layout of Scenario 6, which has the highest efficiency, presents a variation of $-5.19 \%$ leading to a LPC of $85.33 € / M W h$. This means that a saving of 35 M€could be achieved in the project CAPEX.

\section{Conclusions}

This work presented the first optimization framework for designing offshore wind farms composed of floating and moveable 


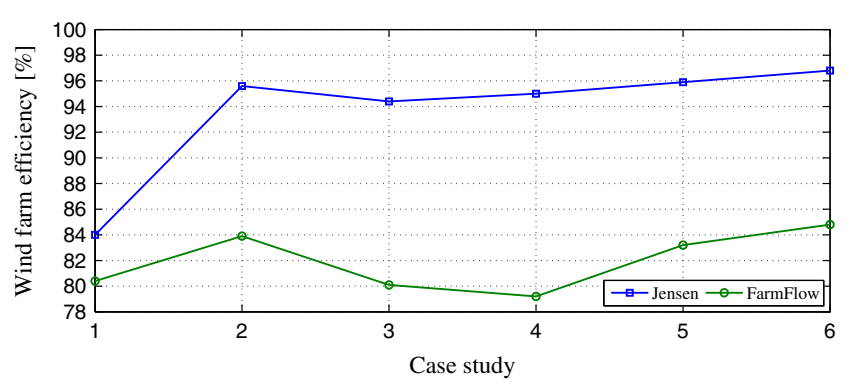

Fig. 11. Wind farm efficiency for both models and all scenarios.

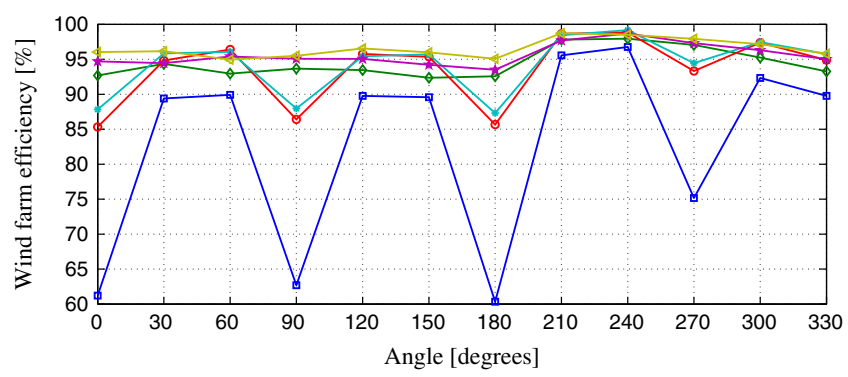

(a) Jensen model

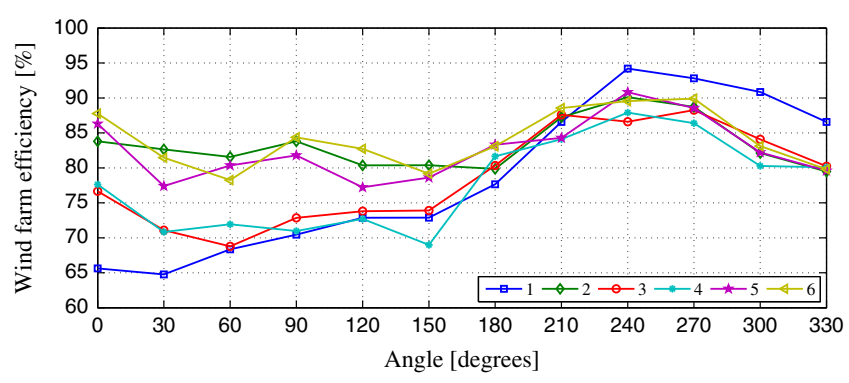

(b) FarmFlow model

Fig. 12. Wind farm efficiency per wind direction for all scenarios and wake models.

Table 2

LPC variation for the different scenarios.

\begin{tabular}{lllllll}
\hline Scenario & 1 & 2 & 3 & 4 & 5 & 6 \\
\hline LPC [\%] & 0 & -4.17 & 0.37 & 1.51 & -3.37 & -5.19 \\
\hline
\end{tabular}

turbines. It demonstrated that the energy gain is further increased through a simultaneous optimization of two factors: firstly, the anchoring locations of the wind turbines - which lead to non-standard grid-based layouts - and, secondly, the turbines locations within the mooring lines for each individual wind direction. The results of the wind farm efficiencies showed relative differences between the Jensen model, used in the optimization process, and FarmFlow, which was applied to validate the efficiency of the final layouts. These results demonstrate the importance of developing accurate wake models which are also fast enough to be applied during the optimization process of future large offshore wind farms. Finally, up to $4.4 \%$ higher wind farm efficiencies were observed when larger maneuver areas were assigned to the turbines, which may be traduced to a $5 \%$ reduction of the LPC and a capital gain of $35 \mathrm{M} €$. The results obtained in this work corroborate that turbine and wind farm developers should cooperate to optimize future offshore wind projects. As future work, the optimization framework can be extended to assess the energy gain for different wind farm sizes and different turbines.

\section{Acknowledgements}

The work has been performed within the projects "Far and Large Offshore Wind (FLOW)". The project is supported by the Ministry of Economic Affairs, Agriculture and Innovation of the Netherlands within the EOS-LT program of Agentschap-NL. The opinion expressed by the authors do not necessarily reflect the position of the Ministry of Economic affairs, nor does it involve any responsibility on its part.

\section{References}

[1] European Wind Energy Association (EWEA), The european offshore wind industry - key trends and statistics. Tech. rep.; 2012.

[2] EWEA, Deep water - the next step for offshore wind energy. Tech. rep.; 2013.

[3] Main(e) International Consulting LLC, Floating offshore wind foundations: industry consortia and projects in the united states, Europe and japan - an overview. Tech. rep.; 2013.

[4] IDEOL; 2014. <http://www.ideol-offshore.com> [accessed 22.08.14].

[5] Sorensen T, Thogersen ML, Nielsen P. Adapting and calibration of existing wake models to meet the conditions inside offshore wind farms. Tech. rep., EMD International $\mathrm{A} / \mathrm{S} ; 2008$.

[6] Rahbari O, Vafaeipour M, Fazelpour F, Feidt M, Rosen MA. Towards realistic designs of wind farm layouts - application of a novel placement selector approach. Energy Convers Manage 2014;81(0):242-54.

[7] Rodrigues S, Bauer P, Pierik J. Modular approach for the optimal wind turbine micro siting problem through cma-es algorithm. In: Proceeding of the fifteenth annual conference companion on Genetic and evolutionary computation conference companion. GECCO '13 Companion. New York, NY (USA): ACM; 2013. p. 1561-8.

[8] Wagner M, Veeramachaneni K, Neumann F, O'Reilly U-M. Optimizing the layout of 1000 wind turbines. In: European wind energy association annual event, european wind energy association. Brussels, Belgium; 2011, pp. 1-10.

[9] Perez B, Minguez R, Guanche R. Offshore wind farm layout optimization using mathematical programming techniques. Renew Energy 2013;53(0):389-99. http://dx.doi.org/10.1016/j.renene.2012.12.007.

[10] Gonzalez JS, Rodriguez GG, Mora JC, Payan MB, Santos JR. Overall design optimization of wind farms. Renew Energy 2011;36(7):1973-82. http:/ dx.doi.org/10.1016/i.renene.2010.10.034.

[11] Grady S, Hussaini M, Abdullah M. Placement of wind turbines using genetic algorithms. Renew Energy 2005;30(2):259-70.

[12] Eroglu Y, Seckiner SU. Design of wind farm layout using ant colony algorithm. Renew Energy 2012;44(0):53-62.

[13] Veigas M, Iglesias G. Potentials of a hybrid offshore farm for the island of Fuerteventura. Energy Convers Manage 2014;86(0):300-8.

[14] Chowdhury S, Zhang J, Messac A, Castillo L. Unrestricted wind farm layout optimization (UWFLO): investigating key factors influencing the maximum power generation. Renew Energy 2012;38(1):16-30.

[15] Rajper S, Amin IJ. Optimization of wind turbine micrositing: a comparative study. Renew Sustain Energy Rev 2012;16(8):5485-92.

[16] Mosetti G, Poloni C, Diviacco B. Optimization of wind turbine positioning in large windfarms by means of a genetic algorithm. J Wind Eng Ind Aerodyn 1994;51(1):105-16.

[17] Lackner MA, Elkinton CN. An analytical framework for offshore wind farm layout optimization. Wind Eng 2007;31:17-31. http://dx.doi.org/10.1260/ 030952407780811401.

[18] Elkinton CN, Manwell JF, McGowan JG. Offshore wind farm layout optimization (owflo) project: an introduction. In: Offshore Wind; 2005.

[19] European Wind Energy Association (EWEA), Wind in our sails - the coming of europes offshore wind energy industry. Tech. rep.; 2011.

[20] Renewable Energy World; 2013. <http://www.renewableenergyworld.com/ rea/news/article/2011/05/a-buoyant-future-for-floating-wind-turbines> [accessed 24.08.14].

[21] Main(e) International Consulting LLC, Japans floating offshore wind projects: an overview; 2013. <http://www.maine-intl-consulting.com/resources/ MIC+Japan+Floating+Projects+May+2013+for+MOWII+Webinar.pdf> [accessed 24.08.14].

[22] Blue H; 2013. <http://www.bluehgroup.com/> [accessed 17.10.013].

[23] LORC. <www.lorc.dk/offshore-wind-farms-map/list> [accessed 29.09.14].

[24] Tesauro A, Rethore P-E, Larsen G. State of the art of wind farm optimization. European Wind Energy Association (EWEA); 2012.

[25] Elkinton CN, Manwell JF, McGowan JG. Algorithms for offshore wind farm layout optimization. Wind Eng 2008;32:67-84. http://dx.doi.org/10.1260/ 030952408784305877.

[26] Igel C, Hansen N, Roth S. Covariance matrix adaptation for multi-objective optimization. Evolution Computat 2007;15(1):1-28.

[27] Hansen N. Reference to cma-es applications; 2009. <https://www.lri.fr hansen/cmaapplications.pdf> [accessed in 26.08.14].

[28] GHWindFarmer. <http://www.gl-garradhassan.com/en/software/ GHWindFarmer.php> [accessed 20.04.14].

[29] WindPRO. <www.emd.dk/WindPRO> [accessed 20.04.14] 
[30] Rodrigues S, Bauer P, Pierik J. A clustering approach for the wind turbine micro siting problem through genetic algorithm. In: 39th Annual conference IECON; 2013.

[31] Andersen SJ, Sorensen JN, Ivanell S, Mikkelsen RF. Comparison of engineering wake models with CFD simulations. J Phys: Conf Ser 2014;524:012161.

[32] Gaumond M, Rethore P-E, Ott S, Pena A, Bechmann A, Hansen KS. Evaluation of the wind direction uncertainty and its impact on wake modeling at the Horns Rev offshore wind farm. Wind Energy 2014;17(8):1169-78.

[33] Barthelmie RJ, Larsen GC, Frandsen ST, Folkerts L, Rados K, Pryor SC, et al. Comparison of wake model simulations with offshore wind turbine wake profiles measured by Sodar. J Atmos Oceanic Technol 2006;23(7):888-901.

[34] Sanderse B. Aerodynamics of wind turbine wakes - literature review. Tech. rep., Energy Research Centre of the Netherlands (ECN); 2009.

[35] Annoni J, Seiler P, Johnson K, Fleming P, Gebraad P. Evaluating wake models for wind farm control. In: Proceedings of the american control conference; 2014, p. 2517-23.

[36] Crespo A, Hernndez J, Frandsen S. Survey of modelling methods for wind turbine wakes and wind farms. Wind Energy 1999;2(1):1-24.

[37] Vermeer L, Srensen J, Crespo A. Wind turbine wake aerodynamics. Prog Aerosp Sci 2003;39:467-510.

[38] Jensen N. A note on wind generator interaction. Tech. rep., Ris National Laboratory; 1983.

[39] Ainslie FF. Calculating the flowfield in the wake of wind turbines. J Wind Eng Ind Aerodyn 1988;27(1):213-24.

[40] Frandsen S, Barthelmie R, Pryor S, Rathmann O, Larsen S, Hjstrup J, et al. Analytical modelling of wind speed deficit in large offshore wind farms. Wind Energy 2006;9(1-2):39-53. http://dx.doi.org/10.1002/we.189. http:// dx.doi.org/10.1002/we.189.

[41] Brower MC, Robinson NM. The openwind deep-array wake model - development and validation. Tech. rep.; 2012. <https://www.awstruepower.com/assets/TheopenWind-Deep-Array-Wake-Model-Development-and-Validation1.pdf>.

[42] Larsen GC. A simple stationary semi-analytical wake model. Tech. Rep. Riso-R1713(EN), Riso National Laboratory, Roskilde; 2009.

[43] Larsen GC, Madsen HA, Bingl F, Mann J, Ott S, Srensen JN, Okulov V, Troldborg $\mathrm{N}$, Nielsen $\mathrm{M}$, Thomsen, Larsen TJ, Mikkelsen R. Dynamic wake meandering modeling. Tech. Rep. Riso-R-1607(EN), Riso National Laboratory, Roskilde; 2007.

[44] Mikkelsen R. Actuator disc methods applied to wind turbines. Ph.D. thesis, Technical University of Denmark; 2003.
[45] Torres P, van Wingerden J-W, Verhaegen M. Modeling of the flow in wind farms for total power optimization. In: International conference on control and automation (ICCA); 2011, p. 963-8.

[46] Churchfield MJ, Lee S, Moriarty PJ, Martinez LA, Leonardi S, Vijayakumar G, Brasseur JG. A large-eddy simulation of wind-plant aerodynamics. AIAA paper; 2012-0537.

[47] Bot E. Farmflow - improved near wake modelling and validation against four full scale wind farms. Tech. rep., Energy Research Centre of the Netherlands; 2012.

[48] Ott S, Berg J, Nielsen M. Linearised cfd models for wakes. Tech. rep., Riso National Laboratory; 2011.

[49] Chen Y, Li H, Jin K, Song O. Wind farm layout optimization using genetic algorithm with different hub height wind turbines. Energy Convers Manage 2013;70(0):56-65.

[50] Chen L, MacDonald E. A system-level cost-of-energy wind farm layout optimization with landowner modeling. Energy Convers Manage 2014;77(0):484-94.

[51] Gonzalez JS, Payan MB, Santos JMR, Gonzalez-Longatt F. A review and recent developments in the optimal wind-turbine micro-siting problem. Renew Sustain Energy Rev 2014;30(0):133-44.

[52] Behnood A, Gharavi H, Vahidi B, Riahy G. Optimal output power of not properly designed wind farms, considering wake effects. Int J Electric Power Energy Syst 2014;63(0):44-50.

[53] Eroglu Y, Seckiner SU. Wind farm layout optimization using particle filtering approach. Renew Energy 2013;58(0):95-107.

[54] Turner S, Romero D, Zhang P, Amon C, Chan T. A new mathematical programming approach to optimize wind farm layouts. Renew Energy 2014;63(0):674-80.

[55] Crespo A, Hernandez J, Fraga E, Andreu C. Experimental validation of the UPM computer code to calculate wind turbine wakes and comparison with other models. J Wind Eng Ind Aerodyn 1988;27(1-3):77-88.

[56] Berge YYE, Byrkjedal, Kindler D. Modelling of offshore wind resources. comparison of a mesoscale model and measurements from fino 1 and north sea oil rigs. In: European wind energy conference and exhibition (EWEC); 2009. <http://dx.doi.org/10.1109/IPEMC.2009.5157547>.

[57] Hansen N, Kern S. Evaluating the cma evolution strategy on multimodal test functions. In: Yao X et al., editors. Parallel problem solving from nature (PPSN VIII). LNCS, Vol. 3242. Springer; 2004. p. 282-91.

[58] 4C Offshore. <www.4coffshore.com/windfarms> [accessed 29.09.14]. 